\title{
34. COMPARISON OF VELOCITIES DETERMINED FROM SONOBUOY, VSP, CORE-SAMPLE, AND SONIC-LOG DATA FROM SITE $765^{1}$
}

\author{
D. Lizarralde ${ }^{2}$ and R. T. Buffler ${ }^{3}$
}

\begin{abstract}
Several types of data were collected at Site 765 that can be used to determine the seismic velocities of the sediments. These data include a sonobuoy profile, a vertical seismic profile, a sonic log, and traveltime measurements through core samples. This study compares the velocity information determined from these various data sets, with emphasis on the analyses of the sonobuoy data. The sonobuoy data were processed and analysed in the $\tau-p$ domain to produce an interval-velocity/depth profile. A comparison of the sonobuoy results with the results of analyses of the other data sets reveals a good agreement among all of the velocity measurements. The velocity/depth profile determined from the analyses of the sonobuoy data is used to convert normal-incidence reflection times to depth, thus enabling the lithologies observed in the cores from Site 765 to be tied to regional reflection profiles.
\end{abstract}

\section{INTRODUCTION}

The physical property of seismic velocity refers to the speed at which seismic energy propagates through a given medium. The accurate determination of the seismic velocities of various units within a sedimentary column is essential to the task of converting to depth the two-way, vertical traveltime of a reflection event observed on a seismic reflection profile. This time-to-depth conversion is especially important if the lithologies observed in cores drilled from the ocean floor are to be extrapolated regionally using regional reflection profiles.

We have analyzed sonobuoy wide-angle-reflection data collected during Leg 123 of the Ocean Drilling Program (ODP) near Site 765 on the Argo abyssal plain. The analysis involves the fitting of ellipses to the $\tau-p$ transformed seismic data to determine interval velocities. The results of the $\tau-p$ analyses are compared with results from the more traditional approach of fitting hyperbolas to the $X-T$ data to determine RMS (root-mean-square) velocities and obtaining interval velocities from Dix's (1955) equation.

The velocity structure determined from the analyses of the sonobuoy data is compared with velocity information obtained from other types of traveltime data collected at Site 765 , including (1) traveltime measurements through core samples taken on board the JOIDES Resolution, (2) traveltime measurements from the sea surface to various depths within the borehole obtained during the VSP (vertical seismic profile) experiment, and (3) sonic log measurements, or traveltimes along the borehole over distances of several meters.

\section{Data Acquisition and Analyses}

Sonobuoy Line 2 (SB Line 2) (Fig. 1) extends from $5.5 \mathrm{~km}$ northeast to $8.0 \mathrm{~km}$ southwest of Site 765 , with the point of closest approach located $\sim 1.5 \mathrm{~km}$ southeast of the site. During the data acquisition the ship was traveling at a speed of approximately 7.5 $\mathrm{kt}$, and shots were fired every $20 \mathrm{~s}$ from two 80 -in. ${ }^{3}$ water guns.

\footnotetext{
${ }^{1}$ Gradstein, F. M., Ludden, J. N., et al., 1992. Proc. ODP, Sci. Results, 123:
} College Station, TX (Ocean Drilling Program).

${ }_{3}^{2}$ Woods Hole Oceanographic Institute, Woods Hole, MA 02543 , U.S.A.

${ }^{3}$ Institute for Geophysics, 8701 Mopac Boulevard, Austin, TX 78759-8375, U.S.A.

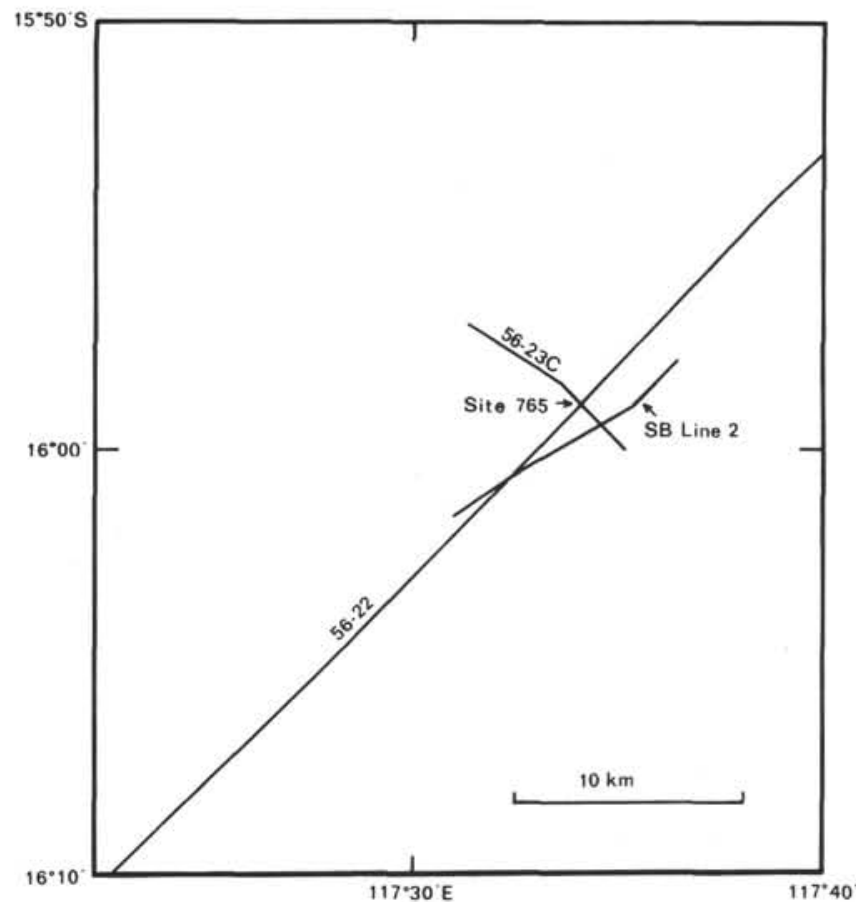

Figure 1. Ship tracks of Sonobuoy Line 2 and BMR Rig Seismic Lines $56-22$ and $56-23 \mathrm{C}$. The location of Site 765 is indicated.

The filter settings of the recording instruments were changed from a pass band of $5-250 \mathrm{~Hz}$ to $5-60 \mathrm{~Hz}$ after the 45 th shot $(\sim 4.5 \mathrm{~km}$ range). The effect of the change in acquisition parameters is clearly seen in a reduced-time plot $(T=T-X / 1.5, \Delta \mathrm{X}=99.0 \mathrm{~m})$ of the direct-wave arrival (arrow, Fig. 2).

The SB Line 2 seismic profile is shown in Figure 3 out to a range of just beyond $13.0 \mathrm{~km}$. The data have been band-pass filtered (5-55 Hz, zero-phase, Butterworth filter) and normalized so that the maximum amplitude of each trace is one. The acquisition-related change in trace character is again evident at $\sim 4.5 \mathrm{~km}$ range. However, with the exception of this one flaw, the quality of the data is good. 


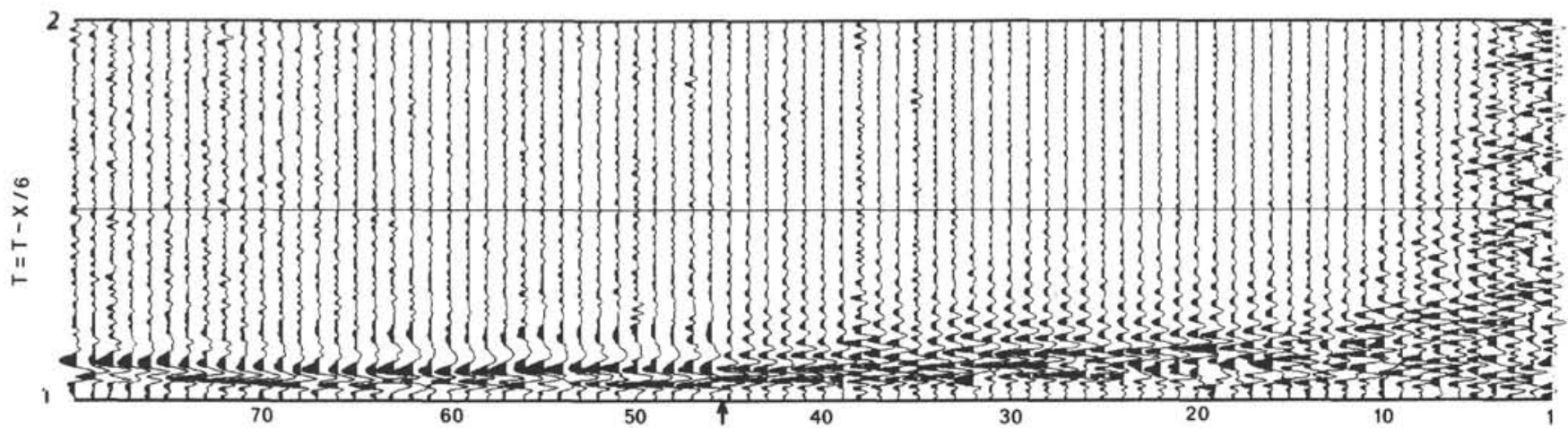

Figure 2. Reduced-time plot of the direct-wave arrival: $T=T-X / 1.5, \Delta X=0.099 \mathrm{~km}$. Arrow denotes change in acquisition filters from 5-250 $\mathrm{Hz}$ to $5-60 \mathrm{~Hz}$.

\section{SONOBUOY DATA ANALYSES}

\section{$\tau-p$ analyses}

The $\tau$ - $p$ analyses of the sonobuoy data involved (1) the transformation of the sonobuoy data into the $\tau-p$ domain and (2) the use of the $\tau_{-p} p$ normal-moveout technique to determine interval velocities from visually fit elliptical trajectories through the $\tau-p$ section. Various aspects of the $X-T$ to $\tau-p$ transformation have been discussed in detail by McMechan and Ottolini (1980), Phinney et al. (1981), Stoffa et al. (1981), and others. The determination of interval velocities by means of the $\tau-p$ normal-moveout method has been presented by Schultz (1982) and Stoffa et al. (1982). Theoretical aspects of the inversion problem thus will be discussed only briefly here.

The sediments in the vicinity of Site 765 are, in general, horizontally stratified. Thus, we may assume that the velocity structure of the sediments consists of a stack of homogeneous, laterally isotropic layers having thicknesses $Z_{\mathrm{j}}$ and slownesses $u_{\mathrm{j}}$ $=1 / V_{\mathrm{j}}$. If we consider a seismic ray path through this stack, then the vertical and horizontal components of slowness along the path are given by

$$
q_{j}=u_{j} \cos i_{j} \text { and } p_{j}=u_{j} \sin i_{j}=p,
$$

where $i_{\mathrm{j}}$ is the angle of the ray in the $j$ th layer with respect to the vertical and the horizontal component of slowness, or ray parameter, $p$, remains constant along the ray path by Snell's law. The total traveltime for a plane wave reflected or refracted from the $n$th interface is then

$$
T=p X+2 \sum_{j=1}^{n} Z_{j} q_{j}
$$

where $X$ is the offset distance between the source and the receiver.

Equation 2 defines a straight line in the $X-T$ domain that is tangent to the traveltime curve at point $(X, T)$, with slope $p$ and intercept time

$$
\tau=T-p X=2 \sum_{j=1}^{n} Z_{j} q_{j} .
$$

The intercept time, $\tau$, is physically interpreted as the two-way, vertical traveltime of the ray with parameter $p$. The $X-T$ traveltime curves can be reparameterized in terms of $\tau$ and $p$. For reflections from the base of a single, horizontal layer, we have

$$
\tau(p)=2 Z q=2 Z\left(u^{2}-p^{2}\right)^{1 / 2} .
$$

This equation describes an ellipse in the $\tau-p$ plane. The $\tau-p$ mappings of the $X-T$ traveltime curves for multiple layers are the sums of ellipses (Schultz, 1976; Deibold and Stoffa, 1981)

$$
\tau_{n}(p)=2 \sum_{j=1}^{n} Z_{j}\left(u_{j}^{2}-p^{2}\right)^{1 / 2} .
$$

The reflection from the first interface is a true ellipse in $\tau$ - $p$, and the reflections from successively deeper interfaces have pseudo-elliptical trajectories.

\section{The $X-T$ to $\tau-p$ Mapping}

An offset seismic section can be mapped into the $\tau-p$ domain by means of the slant stack. The term slant stack refers to the operation of a constant-ray-parameter stack, or summation, along linear trajectories through an $X-T$ seismic section at various intercept times. By slant stacking over a range of ray parameters, $p$, and intercept times, $\tau$, the entire $X-T$ seismic section can be mapped into the $\tau-p$ domain. This transformation is described by the equation,

$$
F\left(\tau_{i}, p_{j}\right)=\sum_{k=1}^{N} f\left(\tau_{i}+p_{j} X_{k}, X_{k}\right),
$$

where $f$ is the seismic section, $F$ the $\tau-p$ mapping, and $N$ the number of $X-T$ traces over which the summation is performed.

Unfortunately, the slant-stack process will introduce artifacts into the $\tau-p$ section if the $X-T$ data are spatially aliased. A trace spacing less than one-half of the wavelength of the highest frequency one wishes to resolve is required to avoid spatial aliasing. The highest frequencies that we consider are $55 \mathrm{~Hz}$, and the horizontal phase velocities observed on the profile beyond $5 \mathrm{~km}$ range are between 2.0 and $3.0 \mathrm{~km} / \mathrm{s}$. To prevent spatial aliasing, the trace spacing would have to be $1 / 2(2 \mathrm{~km} / \mathrm{s} \div 55 \mathrm{~Hz})$, or $18 \mathrm{~m}$. The trace spacing of SB Line 2 is $99 \mathrm{~m}$. Thus, the sonobuoy data are spatially aliased. Figure 4 shows the $\tau-p$ section resulting from a standard slant stack of the sonobuoy data in which all of the traces of the profile were considered in each ray parameter stack. The elliptical trajectories of the reflection events are buried in aliased energy, which appears as linear events fanning out from high to low values of $p$.

A number of windowing and interpolation schemes have been proposed to reduce the problems associated with slant stacking spatially aliased, offset-seismic data (Schultz and Claerbout, 1978; Stoffa et al., 1981; Singh et al., 1989). We use an approach that incorporates a priori knowledge of the water depth, along with the thickness and average velocity of the sediments at Site 765 . With this information one can determine a range of ray 


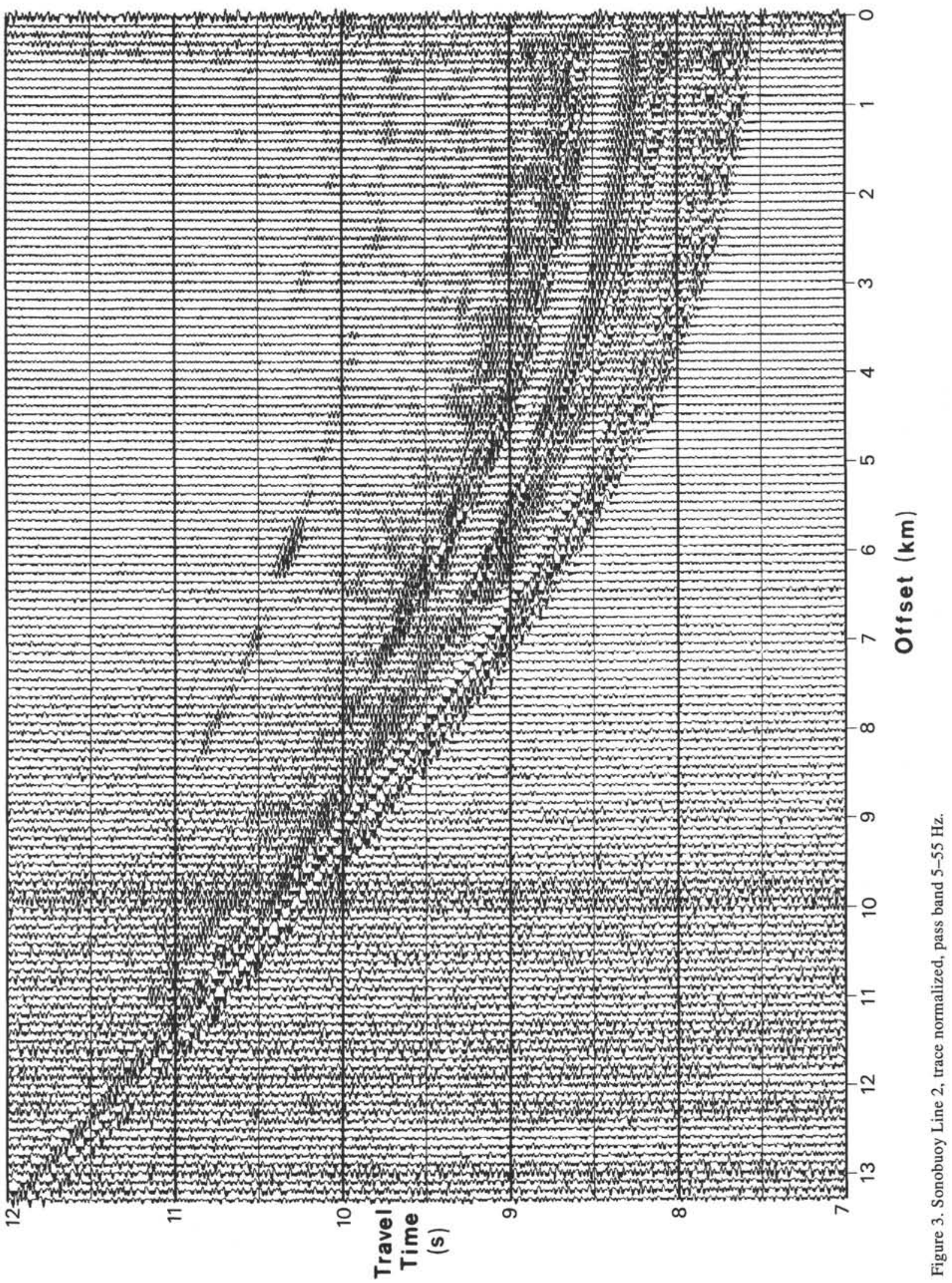




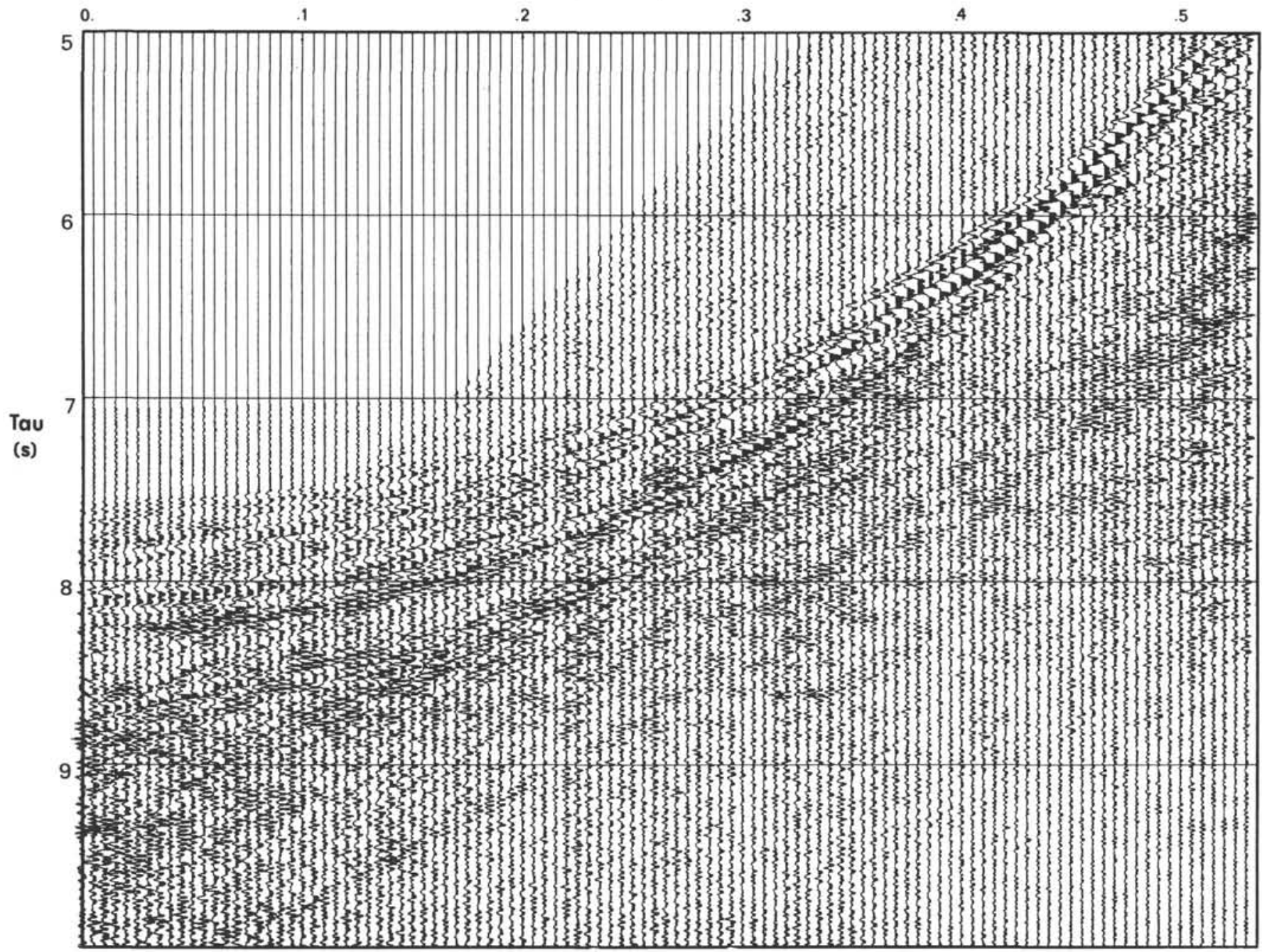

Figure 4. Standard slant stack of SB Line 2 data.

parameter over which each trace should be slant-stacked. This transformation approach is similar to that proposed by Mitchell and Kelamis (1990) who limit the range of ray parameter for each data point using a predetermined velocity model. In our method, the ray parameter of the water-bottom reflection is solved for analytically, and the ray parameter of the basement reflection is determined by a ray trace through a constant-thickness, constantvelocity $(2 \mathrm{~km} / \mathrm{s})$ sedimentary layer. The entire trace is then slant-stacked over this limited range of ray parameter. This transformation method, which we refer to as a ray-traced slant stack, is not especially sensitive to the assumed parameters, is extremely fast, and produces an excellent result (Fig. 5).

\section{Exact normal moveout in $\tau-p$}

Schultz (1982) and Stoffa et al. (1982) presented a layer-stripping method for determining interval velocities from a $\tau-p$ section based on the traveltime equations in $\tau-p$. Equation 5 indicates that the reflections from a layered stack appear as the sums of ellipses in $\tau-p$. The reflection from the first interface is a true ellipse, and the reflections from deeper interfaces are pseudo-elliptical. Equation 5 can be rewritten in terms of the two-way, zero-offset (normal-incidence) traveltime, $t_{j}=2 Z_{j} / V_{j}$ as (Stoffa et al., 1982)

$$
\begin{gathered}
\tau_{n}(p)=2 \sum_{j=1}^{n} t_{j}\left(1-V_{j}^{2} p^{2}\right)^{1 / 2}, \text { or } \\
\tau_{n}(p)=\tau_{n-1}(p)+2 t_{n}\left(1-V_{n}^{2} p^{2}\right)^{1 / 2},
\end{gathered}
$$

where $\tau_{n-l}(p)$ is the total vertical traveltime for a ray with parameter, $p$, reflecting off the $(\mathrm{n}-1)$ th interface.

The earliest reflection of the $\tau-p$ section is a true ellipse. Thus, the interval velocity of the first layer can be determined by simply fitting an ellipse to this event. This is essentially ray tracing in the $\tau-p$ domain. Equation 8 can be used to determine the interval velocities of the next layer by "moving out" the $\tau-p$ section to a new datum, $t_{1}$. The reflection event from the first interface is thus made horizontal, and the trajectory of the reflection event from the next interface becomes a true ellipse from which the interval velocity of this layer can be determined. The procedure continues in this fashion until all of the reflection events on the $\tau-p$ section have been corrected to their two-way, zero-offset, vertical traveltime. If the interval velocities used to move out the reflections are correct, the resulting moveout-corrected $\tau-p$ section will consist of a sequence of horizontal events.

This method is similar to the standard normal-moveout correction applied to multifold seismic data prior to stacking. However, 
$\mathrm{P}(\mathrm{s} / \mathrm{km})$

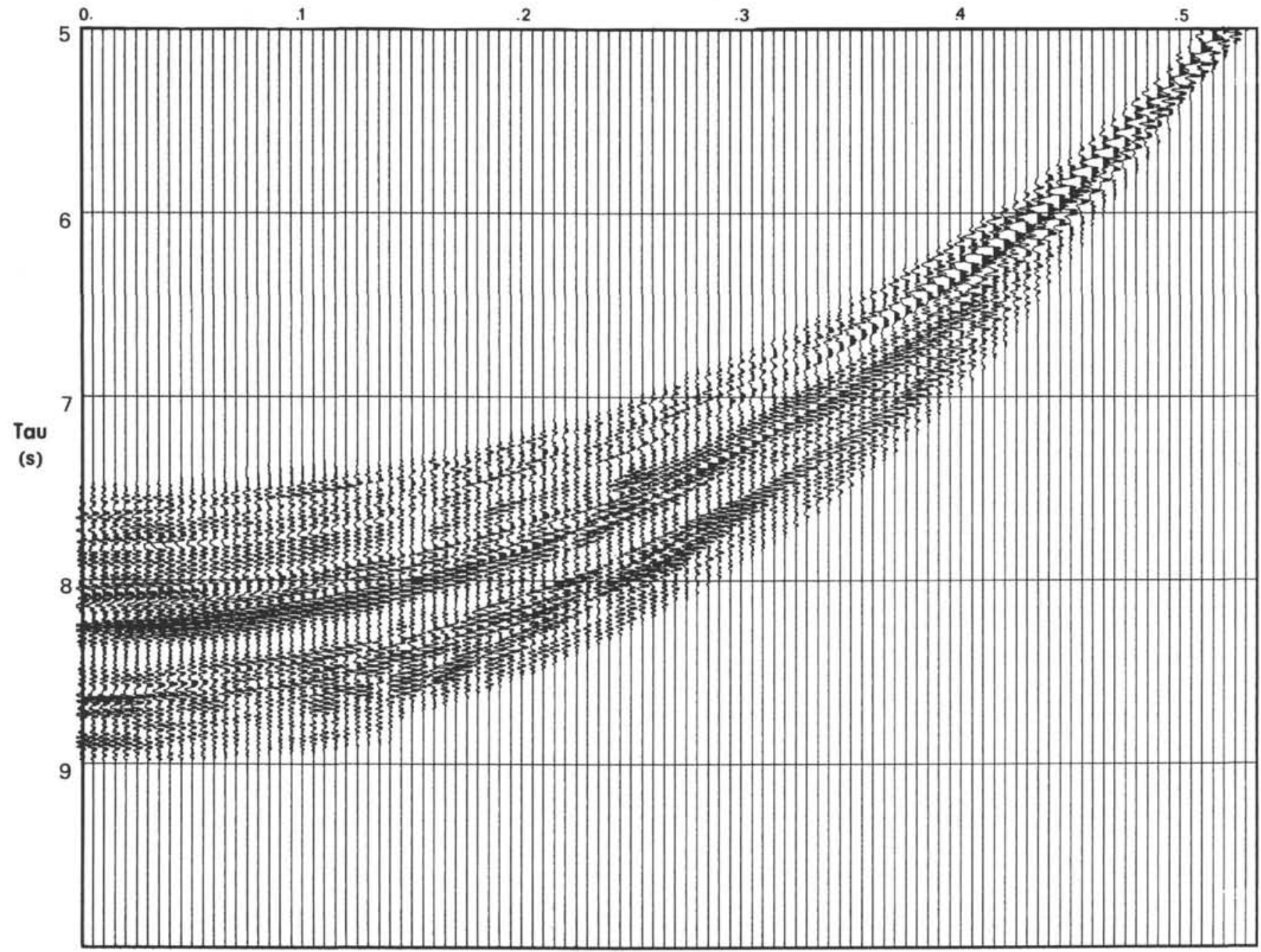

Figure 5. Ray-traced slant stack of SB Line 2 data.

the standard normal-moveout correction in $X-T$ is a two-term approximation to the hyperbolic traveltime equation, which is only valid for small angles of incidence. The moveout correction in $\tau-p$ is exact for all angles. The method is thus referred to as exact normal moveout.

This procedure was carried out using an interactive computer program at the University of Texas Institute of Geophysics. The $\tau-p$ section is displayed on the computer screen, a normal-incidence time is picked for a reflection event, several velocities are chosen and the corresponding ellipses drawn until a good fit to the event is found. The $\tau-p$ section is then moved out, and the fit is judged good if the event becomes horizontal. The procedure continues until all prominent events have been moved out.

The ellipses that were fit to the SB Line 2 data are shown in Figure 6. The resulting moveout-corrected section is shown in Figure 7A, with depths below seafloor and layer velocities indicated next to the layer-interface numbers on the right of the figure. Most of the events are now horizontal, which suggests that the interval velocities used to apply the moveout correction are good. The prominent linear "break" in the $\tau$ - $p$ section between 0.20 and $0.29 \mathrm{~s} / \mathrm{km}$ is the effect of resetting the filter parameters during acquisition and should not be interpreted as the effect of faulting, which the break may resemble. Although the character of the traces changes abruptly across the break, the moveout of the reflection events is unaffected. Thus, the accuracy of the moveout corrections that were applied to the various reflections can still be judged on the basis of whether the reflections have become horizontal.

In Figure 7B, the velocity/depth function is overlain on the single-channel, vertical seismic reflection record that was recorded at the same time as the sonobuoy data. The gain of the single-channel data was adjusted using a 500 -ms, automatic-gaincontrol operator. The data were filtered with a $15-$ to $55-\mathrm{Hz}$, band-pass filter, and each trace was mixed with its nearest neighbors to improve the signal/noise ratio.

Several features of the reflection section are worth mentioning. First, the events between 8.0 and $8.3 \mathrm{~s}$ dip gently to the northeast. The sonobuoy line was shot in the "updip" direction relative to these events, and the interval velocities for these normal-incidence times may be slightly high. The velocity/depth function does indicate a high-velocity zone between 8.0 and $8.15 \mathrm{~s}$. The dip is too small, however, to account for such an abrupt increase in velocity. Notice that the large velocity contrasts at the top and bottom of the high-velocity zone correlate with the largest reflection amplitudes observed on the section.

Second, the reflections in the center of the section are offset by what appears to be a fault between 8.0 and $8.5 \mathrm{~s}$. Also note the roughness of the basement reflection, which occurs at around 


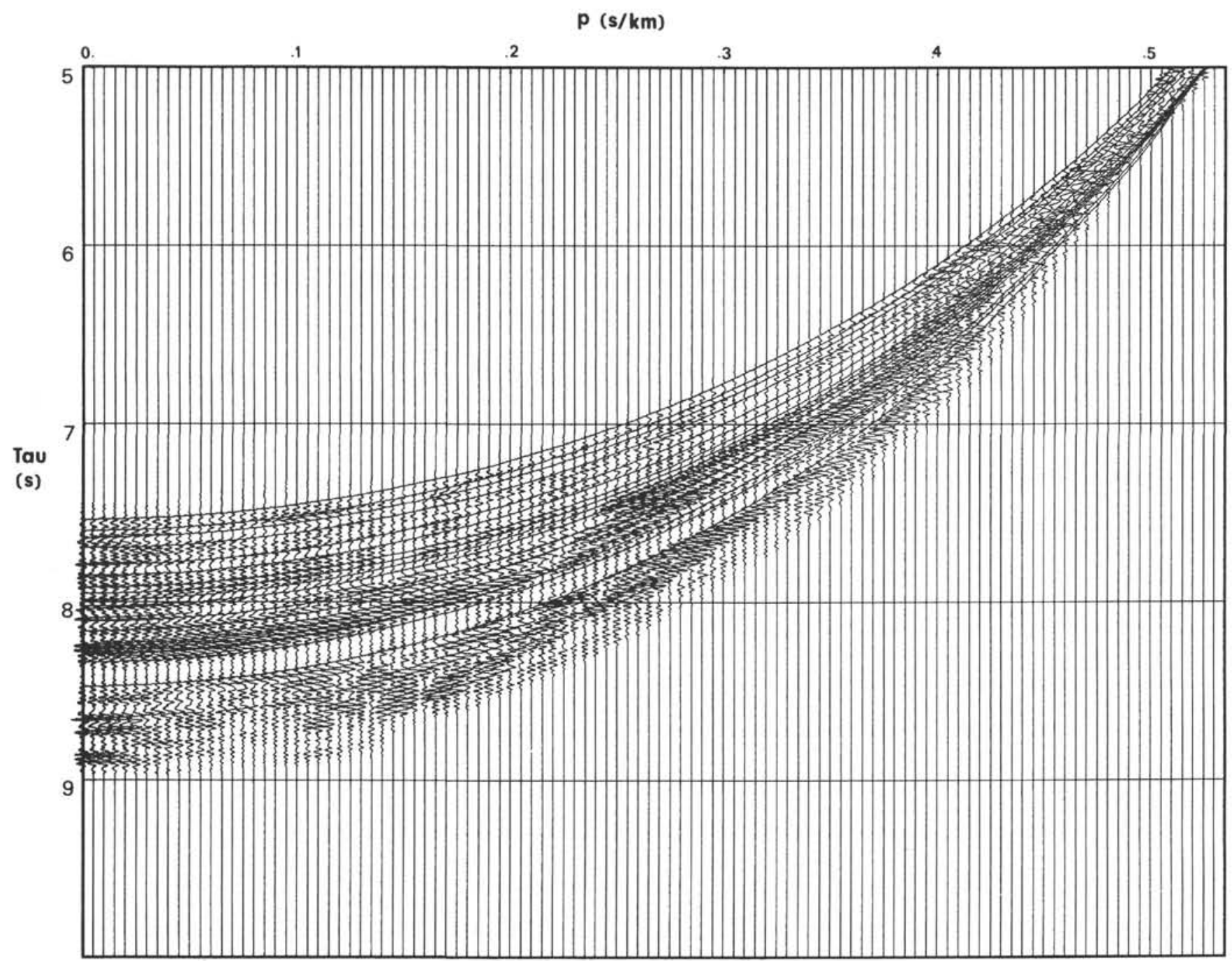

Figure 6. $\tau-p$ section of Figure 5 with fit ellipses drawn in.

$8.5 \mathrm{~s}$. The presence of dip and faulting within the sedimentary section and significant relief of the basement topography may introduce some error into the velocity analyses, which assumes a horizontally stratified media. These features, however, are not too pronounced and probably do not significantly affect the results.

\section{Interval velocities from semblance in $X-T$}

The method of determining interval velocities from stacking velocities using Dix's (1955) equation is very common in the analyses of multifold seismic data. The stacking velocity, $V_{s}$, is determined as that velocity which produces the "best fitting" hyperbola,

$$
T_{X, n}^{2}=T_{0, n}^{2}+\frac{X^{2}}{V_{s, n}^{2}},
$$

in the sense that the amplitudes of the traces along the hyperbolic trajectory maximize some coherency statistic, typically semblance (Taner and Koehler, 1969). Stacking velocities can be chosen for various reflection events from a velocity spectra plot, which is typically a contour plot of semblance values determined for a range of velocities at various intercept times. If the stacking velocities are assumed equal to the RMS velocities, then Equation 9 is the two-term approximation to the traveltime equation for reflections from the $n$th interface (Dix, 1955). The interval velocities can be determined from Dix's equation (1955) as

$$
v_{n}^{2}=\frac{V_{R M S, n}^{2} T_{0, n}^{2}-V_{R M S, n-1}^{2} T_{0, n-1}^{2}}{T_{0, n}-T_{0, n-1}},
$$

where $v_{\mathrm{n}}$ is the interval velocity of layer $n$.

Equation 9 is based on a small-angle approximation which is only valid for small offset distances. As traces at larger offsets are considered, the stacking velocity determined from the best-fit hyperbola will diverge from the true RMS velocity. The limited bandwidth of the data also introduces uncertainties in the determination of stacking velocities and intercept times. Equation 10 is sensitive to errors in the values of RMS velocity and intercept time. Stoffa et al. (1982) presented examples from real and synthetic data suggesting that even in the best conditions, errors in interval velocities determined by this approach can easily be on the order of $5 \%-10 \%$.

Figure 8 is a velocity spectra plot of semblance values between 0.4 and 1.0. These spectra were calculated from the first $4.5 \mathrm{~km}$ of SB Line 2. The picked zero-offset times and RMS velocities used for calculating interval velocities are indicated. The solid line passes through the picked maxima. The spectra indicate an upper interval relatively incoherent events between 7.55 and 
A

p $(\mathbf{s} / \mathbf{k m})$

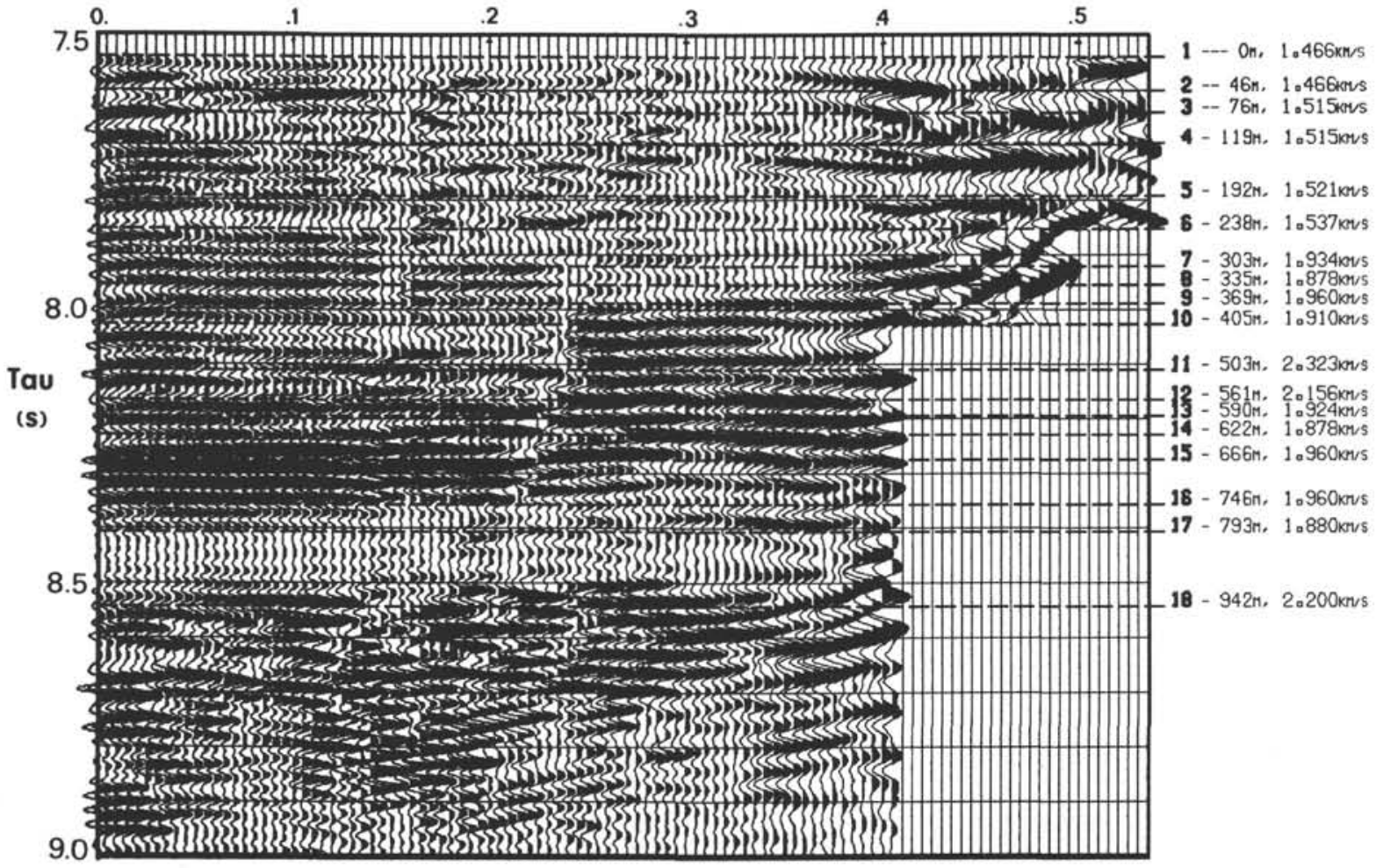

B

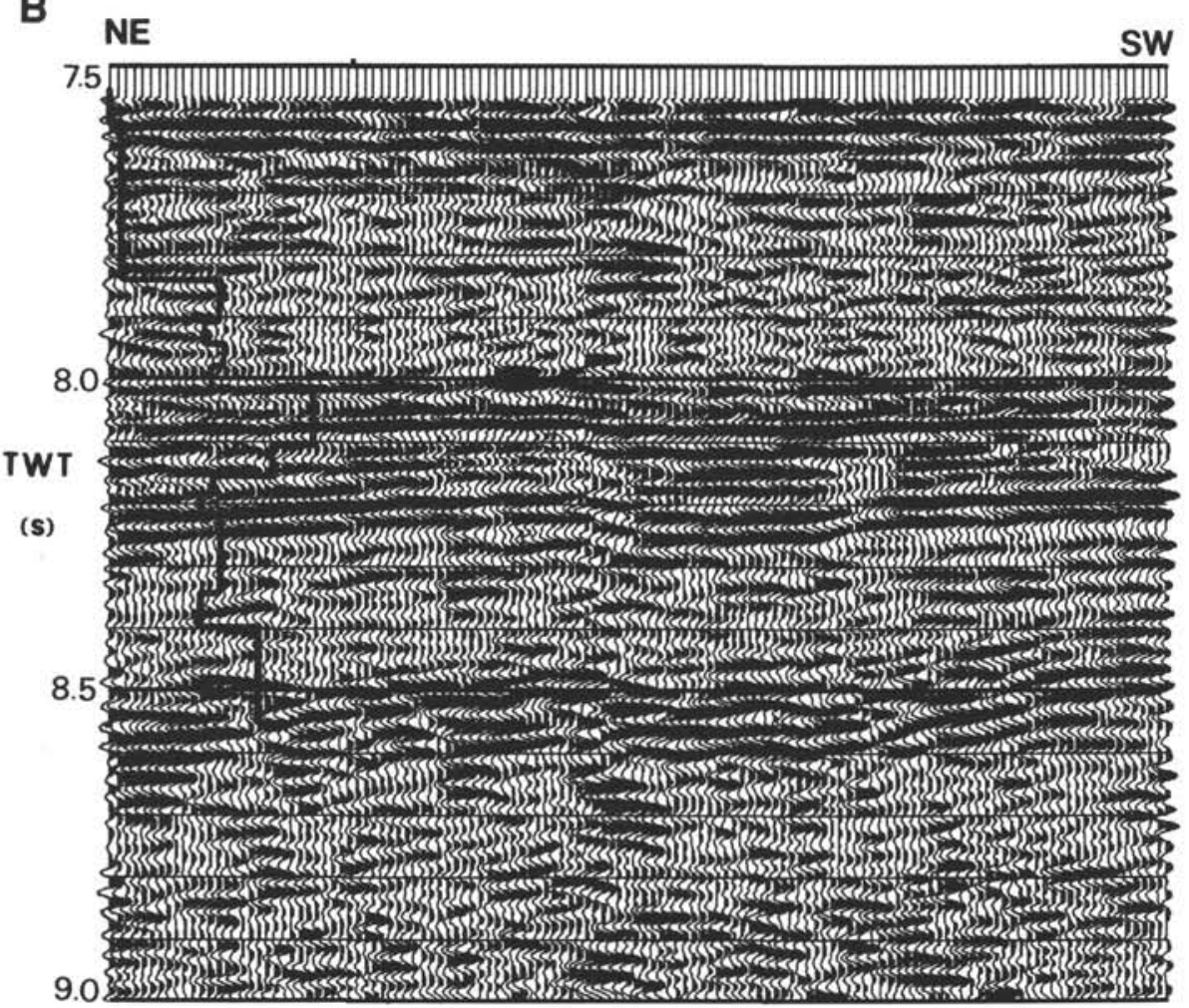

Figure 7. A. Moved-out $\tau-p$ section with interval velocities and depth below seafloor indicated next to the layer-interface numbers. B. Single-channel reflection section along SB Line 2 (Fig. 1) with the interval-velocity function from (A) superimposed at the left of the figure. Northeast is to the left, southwest to the right. 


\section{RMS Velocity $(\mathrm{km} / \mathrm{s})$}

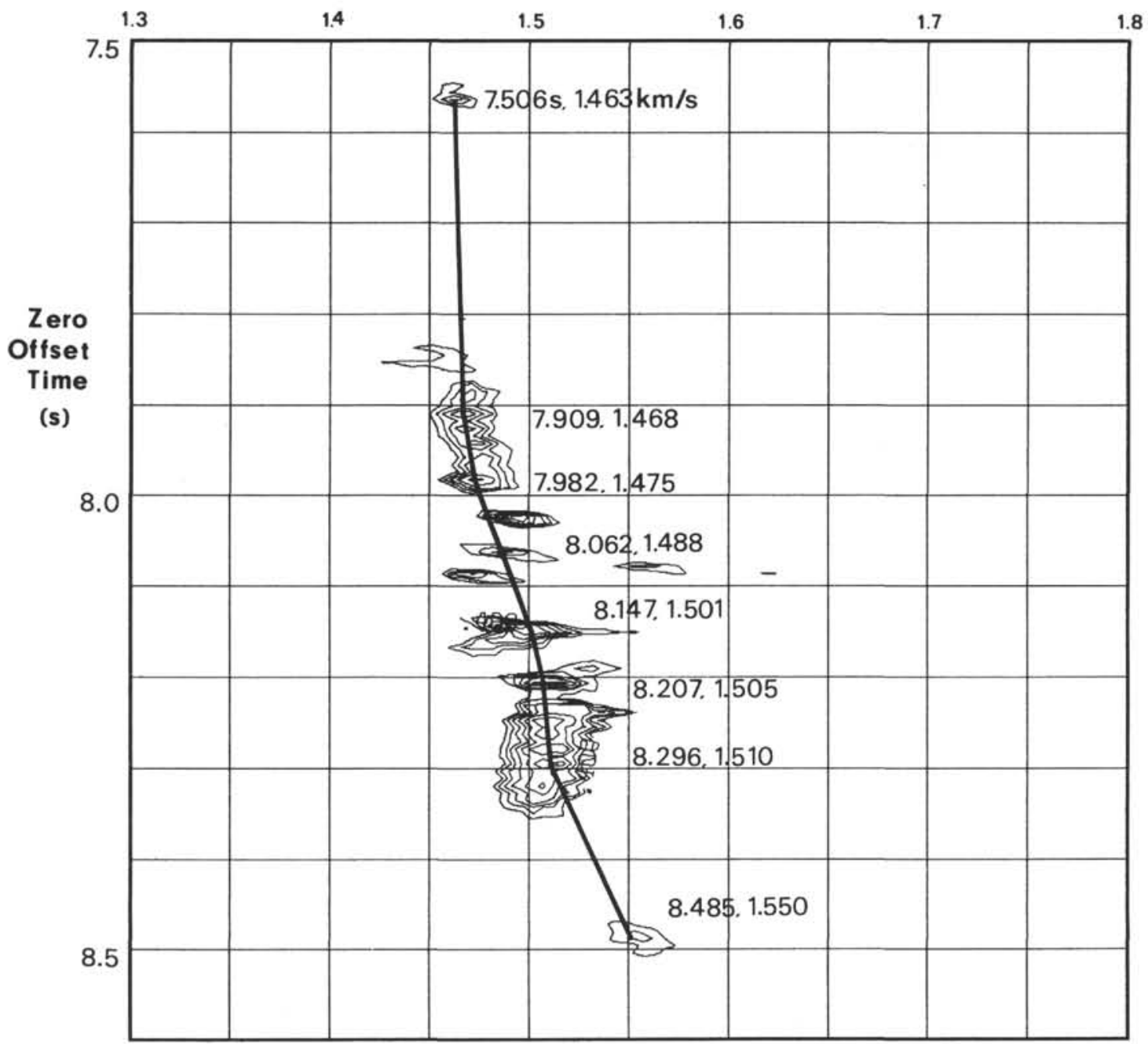

Figure 8. Contour of semblance values from 0.4 to 1.0 (contour interval 0.1 ). Zero-offset times and RMS velocities used in the calculation of interval velocities of Figure 9 are indicated. Solid line passes through the picked maxima.

$7.85 \mathrm{~s}$. The events between 8.0 and $8.1 \mathrm{~s}$ are less coherent than the other events in the 7.9-8.35 s interval. This 8.0- to 8.1-s interval coincides with the high velocity zone $(2.32 \mathrm{~km} / \mathrm{s})$ determined by the $\tau-p$ analyses and also coincides with the maximum scatter in the velocities measured from the core samples (discussed below).

The interval velocities determined from the semblance picks are shown in Figure 9 along with the interval velocities determined from the $\tau-p$ analyses. The two results are generally similar. The velocity of the interval between 750 and 1000 mbsf (meters below seafloor) determined from the semblance pick at $8.5 \mathrm{~s}$ is considerably higher than the velocity determined from the $\tau$ - $p$ analyses. The semblance values at $8.5 \mathrm{~s}$ are somewhat low (0.5), however, which reflects the discontinuous nature of the basement reflection.

The interval velocities determined from the $\tau-p$ analyses are preferred because of the better resolution of the method and because the method involves no offset-dependent approximations. A similar semblance analyses was performed on the $\tau$ - $p$ transformed data, where elliptical trajectory based on RMS velocities were scanned. The semblance plot and resulting interval velocities were virtually identical to those determined from the analyses of the $X-T$ data.

\section{VELOCITIES FROM VSP, CORE SAMPLES, AND THE SONIC LOG}

\section{The VSP Data}

A VSP experiment was conducted in the cased Hole 765D (Bolmer et al., this volume). The VSP tool occupied 35 stations spaced $12-30 \mathrm{~m}$ apart between 186.0 and 915.0 mbsf. Shots were fired from a 1000 in. ${ }^{3}$ air gun and a 400 in. ${ }^{3}$ water gun. During the experiment, arrivals detected by the VSP geophones were monitored in the Underway Geophysics Laboratory, and the tool remained at a station until clear signals from at least five shots from each gun were recorded. The data from each station were subsequently edited, and the good traces stacked to enhance the signal/noise ratio. The resulting VSP stacked section for the air gun shots is shown in Figure 10.

Interval velocities can be determined from the VSP data by dividing the distance between two stations, $d z$, by the difference of the arrival times, $d t$, of the direct wave recorded at the two 
Interval velocities from SB Line 2

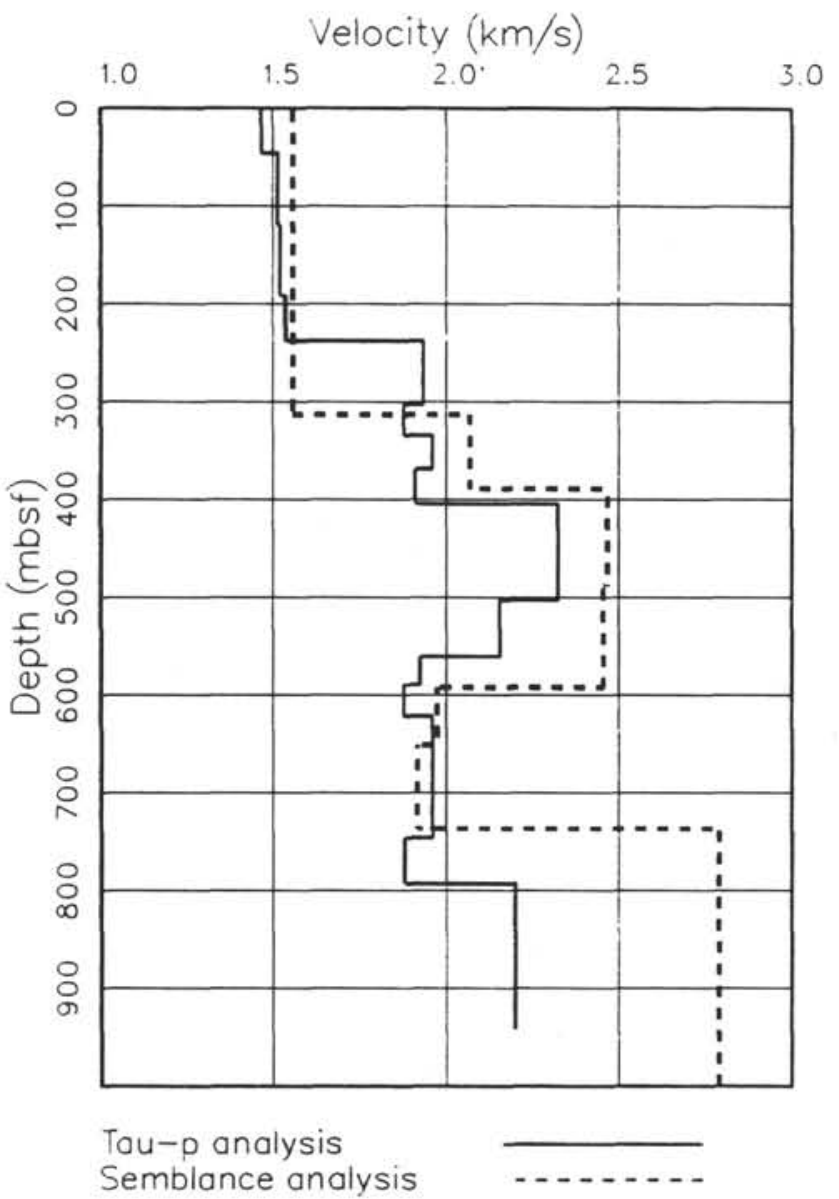

Figure 9. Interval velocities determined from the semblance picks (dashed line) and the $\tau-p$ analyses (solid line).

stations. The depth of the tool in the hole was determined by the wireline-out depth at the logging winch. The arrival-time differences, or $d t$ 's, were determined from similar pulse-phase peaks of first breaks on adjacent station traces (Bolmer et al., this volume). The velocities determined for the intervals between each VSP station are plotted as the solid line in Figure 11.

There is a significant amount of variability in the VSP interval velocities. The velocity values vary by $\pm 0.1-0.2 \mathrm{~km} / \mathrm{s}$ about a mean of $\sim 2.0 \mathrm{~km} / \mathrm{s}$. Some of this fluctuation may be a result of errors in the positioning of the tool in the hole. At a station spacing of $12-30 \mathrm{~m}$, a $1.0-2.0 \mathrm{~m}$ error in $d z$ could easily account for the variation in the interval velocities. Such an error in the determination of the depth of the tool is possible, given the length of the wireline and the difficulties encountered in setting the tool in casing during the experiment (see Bolmer et al., this volume).

The effect of errors in $d z$ will be reduced if velocities are calculated over larger intervals. However, there will be a loss of resolution in the velocity profile if the velocities are calculated over an interval of three VSP stations, say, as opposed to two. By computing a "weighted-average" interval velocity between each VSP station the effect of errors in $d z$ can be reduced while maintaining the resolution of the experimental station spacing.

A weighted-average interval velocity between VSP Stations 2 and 3 , for example, can be computed as the average of the computed interval velocities between Stations 1 and 3 and between Stations 2 and 4. This is, in a sense, a signal-enhancing,
Travel Time (s)

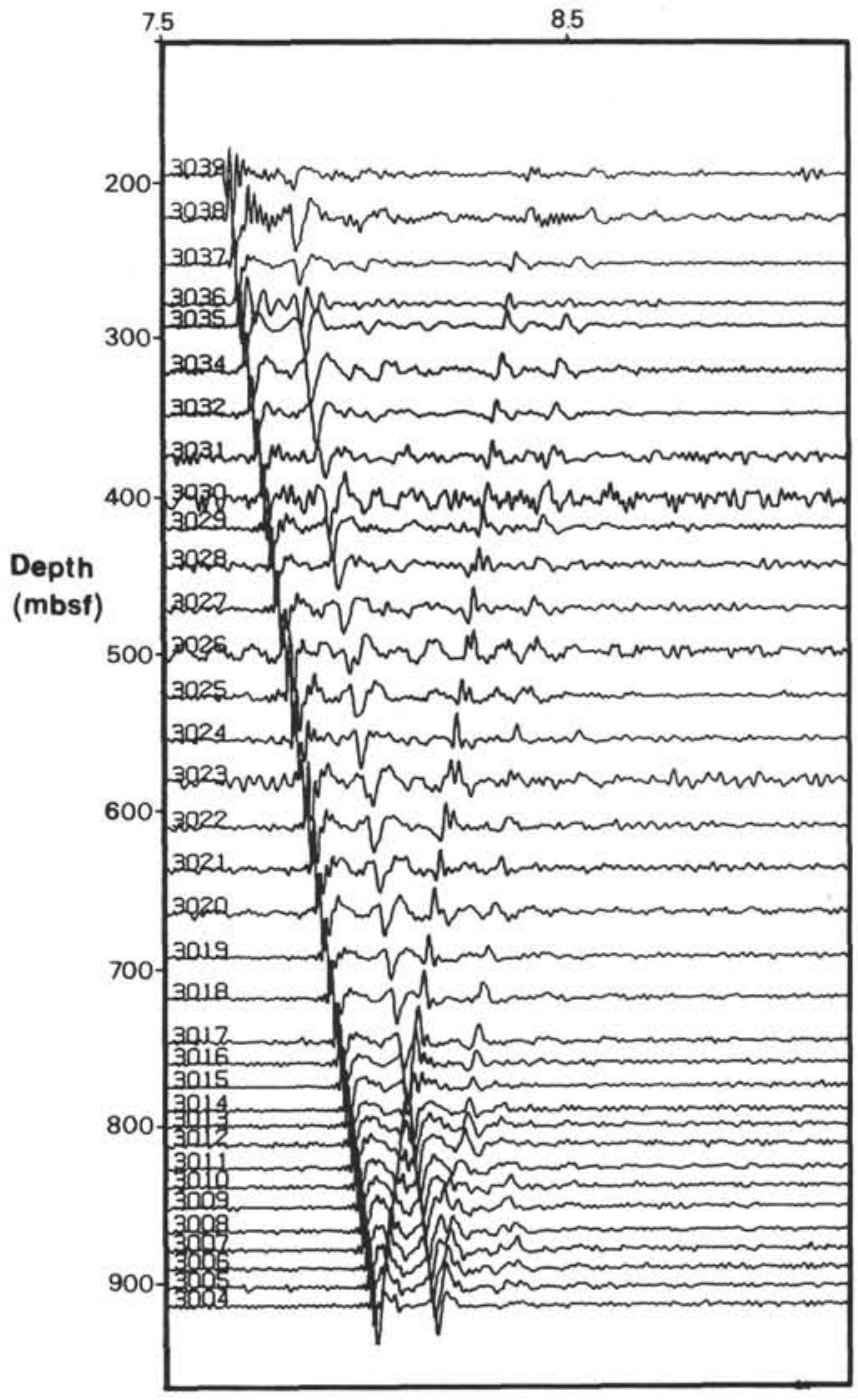

Figure 10. Stacked, vertical-component VSP section of air-gun arrivals.

low-pass filter, in that noise (the effect of presumably random errors in the determination of the depth of the tool) is reduced, while the velocity determined for a particular interval is influenced by the velocities of the intervals above and below (as if the velocity function had been convolved with a triangular operator). The resulting weighted-average interval velocities are plotted in Figure 11 as a heavy, dot-dash line. The fluctuations in the velocities are reduced and the agreement between the VSP-determined velocities and those determined from the sonobuoy (light, dashed line) is improved, particularly in the interval between 550 and $800 \mathrm{mbsf}$. The high velocity zone indicated by the VSP results between 350 and $500 \mathrm{mbsf}$ roughly corresponds with high velocity zone indicated by the sonobuoy results between 400 and 500 mbsf.

\section{Core Sample and Sonic Log Velocities.}

Compressional ( $p$-wave) velocities were determined in the laboratory for core samples by dividing the length of the sample by the traveltime of a $500-\mathrm{kHz}$ compressional wave through the sample. In general, laboratory-measured velocities differ from in-situ velocities because of differences in confining pressure, drilling disturbance of the sediments, and changes in pore-fluid 


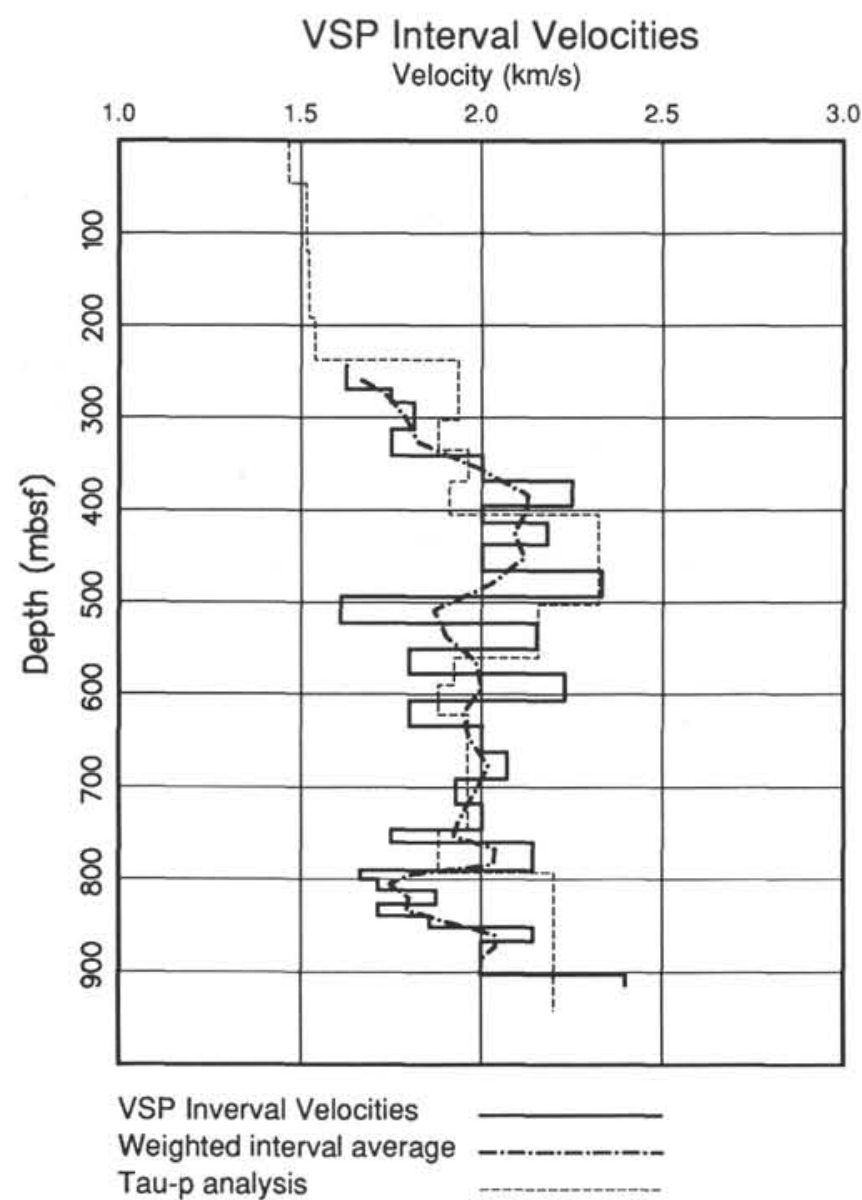

Figure 11. Interval velocities determined from the VSP (solid line), weighted-average interval velocities determined from the VSP (dot-dash line), and the interval velocities determined from the sonobuoy (dashed line).

conditions. These factors all tend to decrease the bulk modulus of the sample relative to the in-situ bulk modulus. As a result, $p$-wave velocities measured in the laboratory tend to be systematically low (Carlson et al., 1986).

$P$-wave velocities were also measured using the Schlumberger sonic-log tool. This tool measures the traveltime of $p$-waves from a $50 \mathrm{kHz}$ source to an array of receivers located 8,10 , and $12 \mathrm{ft}$ from the source. The seismic energy travels from the source (located on the tool) through the borehole fluid, along the formation wall, and then back through the fluid to the receivers located on the tool. The use of an array of receivers compensates for variations in traveltime due to the rugosity of the formation wall and inhomogeneities of the borehole fluid.

The velocities determined from the core samples and sonic logs are plotted in Figure 12 along with the interval velocities determined from the sonobuoy and VSP. The sonic log data were convolved with a 19-point (15 cm/point), unit-area, triangular weighting function to filter out high frequencies. Also shown in Figure 12 is the empirical velocity/depth curve (dashed line) of Carlson et al. (1986), determined from a compilation of lithology/vertical-reflection correlations from 154 DSDP sites worldwide. Carlson et al. (1986) suggested that the empirical velocity/depth function for oceanic sediments they obtained,

$$
V(\mathrm{~km} / \mathrm{s})=1.59 e^{(0.332)},
$$

Comparison of Velocities, Site 765

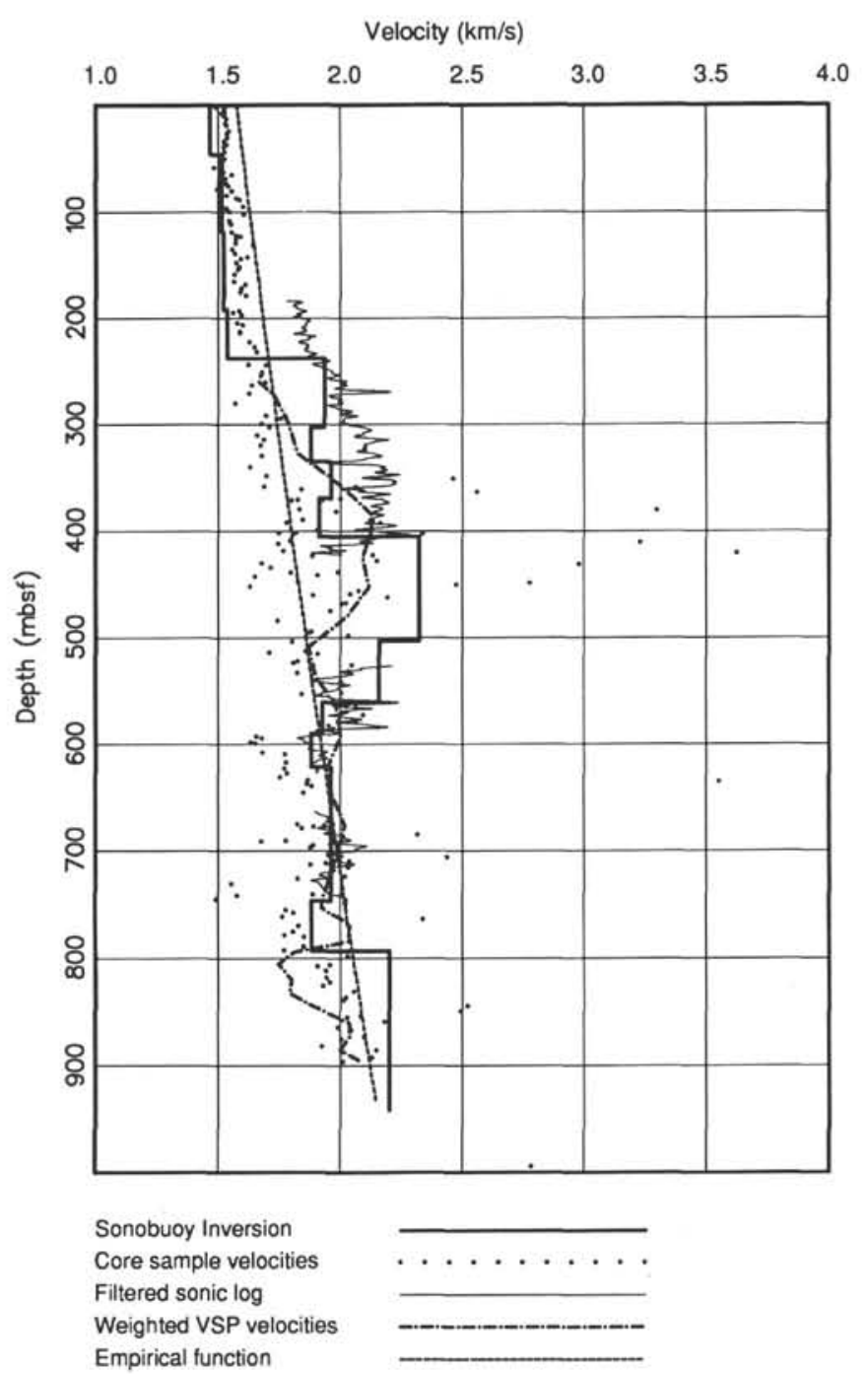

Figure 12. Site 765 velocities determined from core-sample measurements (dots), the sonobuoy (heavy line), the sonic log (medium line), and the VSP (light line). The dashed line is the empirical velocity/depth curve for oceanic sediments by Carlson et al. (1986).

is independent of age and composition of the sediment and depends only on overburden pressure and temperature, which are related to depth of burial. The trend of the core-sample velocities generally follows the empirical function. However, the core sample velocities fall systematically below the values of the empirical function.

\section{DISCUSSION}

The velocities from the sonobuoy, the VSP, and the sonic log agree reasonably well over most intervals. Although in most cases the core-sample velocities are predictably lower than the other velocity measurements, changes in the core sample velocities between 550 and 900 mbsf agree with similar changes in the other velocity measurements. The largest differences between the various results occur in the intervals between $0-240$ mbsf and 400500 mbsf.

Cores recovered from 0 to 190 mbsf consist mostly of unlithified nannofossil ooze. Lithification of the sediments gradually 
increases from 190 to 379 mbsf, at which depth a fairly marked increase in lithification occurs. In the interval 0-240 mbsf, the velocities determined from the sonobuoy $(1.47-1.54 \mathrm{~km} / \mathrm{s})$ are near the velocity of water, reflecting the highly unconsolidated nature of the sediments. However, these velocities are lower than both the velocities determined in the laboratory and those predicted by the empirical function. The sonic log data begin at approximately $190 \mathrm{mbsf}$, with values of $\sim 1.75 \mathrm{~km} / \mathrm{s}$, significantly greater than the other measurements and the empirical function. Thus, the sonobuoy velocities are probably too low within the 0-240 mbsf interval. The empirical function probably gives a good estimate of the velocity to a depth of around $150 \mathrm{mbsf}$, at which point a stronger velocity gradient is necessary to bring the velocity values nearer those of the sonic log.

The abrupt increase in the sonobuoy velocity profile at 240 mbsf does not coincide with any similarly abrupt change in core lithology. (This depth does roughly coincide, however, with a somewhat abrupt increase in drilling disturbance and decrease in core recovery at $231 \mathrm{mbsf}$.) Nevertheless, this increase brings the sonobuoy velocities in line with those of the sonic log and VSP. The sonobuoy and sonic log velocities agree well within the $240-400$ mbsf interval.

The sonobuoy velocity profile again abruptly increases at 400 mbsf from 1.91 to $2.32 \mathrm{~km} / \mathrm{s}$, defining the top of a high-velocity layer that extends to $500 \mathrm{mbsf}$. The VSP velocities also increase significantly between 325 and 400 mbsf. This increase probably reflects the increase in lithification observed in the cores at 380 mbsf and the presence of a high velocity pebble conglomerate between 460 and $475 \mathrm{mbsf}$. However, the velocities from the VSP in the $400-500 \mathrm{mbsf}$ interval are $0.30 \mathrm{~km} / \mathrm{s}$ lower than those determined from the sonobuoy. One explanation for this difference may be a lateral variation in the thickness of the conglomerate layer. The scatter of the core-sample velocities illustrates the variability of the velocities within the conglomerate (some of the velocities are greater than $4 \mathrm{~km} / \mathrm{s}$ ). Horizontal velocities (which are measured by the sonobuoy) may be higher than vertical velocities in this interval because of the presence of the high-velocity material within the conglomerate, which may be more extensive laterally than directly beneath the drill site. The slight dip of the reflections between 8.0 and $8.3 \mathrm{~s}$ observed on the single-channel profile may result in slightly higher interval velocity determinations from the sonobuoy.

Given the good agreement of the sonic log, VSP, and core-sample velocities between 500 and 550 mbsf, the sonobuoy velocities in this interval seem somewhat high. Likewise, the VSP velocities below $800 \mathrm{mbsf}$ seem somewhat low. In general, however, all of the velocity measurements agree well below $550 \mathrm{mbsf}$. Even the small changes in the sonobuoy profile at 600 and $750 \mathrm{mbsf}$, seemingly below the resolution of the method, appear to be verified by the sonic log and core-sample velocities.

Because the agreement of the sonobuoy velocities and those of the other measurements is good, the sonobuoy velocities can be used with confidence to estimate depths to reflections observed on regional multifold seismic profiles. In Figure 13, the sonobuoy velocity profile is overlain on a portion of the BMR (Australia Bureau of Mineral Resources) Rig Seismic Line 56-23C. This line trends southeast (approximately perpendicular to SB Line 2) and passes over Site 765 and the closest approach of SB Line 2 to the site (Fig. 1). The depths to the seismic sequence boundaries interpreted by Buffler (1989) are indicated at the right of the figure. These depths can be used to tie the seismic sequences to the lithologies observed in the cores recovered at Site 765.

\section{CONCLUSION}

The acquisition of sonobuoy, VSP, sonic log, and core-sample traveltime data at Site 765 provided a rare opportunity to compare the velocity information that can be derived from these types of data. None of the data are perfect. A change in acquisition parameters in the middle of the sonobuoy experiment makes the sonobuoy data less than ideal. The depths of the VSP stations may contain significant errors due to the difficulties setting the tool in the casing and the considerable water depth of the hole. The sonic $\log$ data do not cover the entire length of the hole and are sporadic within the logged interval. The core samples were affected by drilling disturbance, and traveltimes were not measured at in-situ conditions.

Nevertheless, the resulting velocities from all data types agree well. Although the velocities determined from the core samples are generally lower than those determined from the other data, the difference is systematic and abrupt changes in core-sample velocities generally match similar changes in the other velocity measurements. The "scatter" of the interval velocities determined from the VSP data associated with uncertainties in the positioning of the tool were reduced by computing a weighted-average interval velocity between each VSP station. The velocities determined in this way agree well with the trend of the other velocity determinations.

The velocities determined from the sonobuoy for the interval 400-500 mbsf may be somewhat higher than the vertical velocities for similar depths in the vicinity of Site 765. This is probably a result of (1) the presence of high-velocity material within a pebble conglomerate at these depths, which may vary laterally, and (2) the presence of a slight dip in the strata at these depths. Below 550 mbsf all of the velocity measurements are in agreement.

Of the four types of velocity measurements, the sonobuoy profile provides the least direct measure of seismic velocity at a particular location and depth. However, because it is an indirect measure, sonobuoy data are considerably less difficult and less expensive to acquire. The good agreement of these various data types is significant in that it provides a verification of the sonobuoy method, and in particular the $\tau-p$ approach. These results suggest that given good quality data and a reasonably uniform geologic setting, sonobuoys can be used to determine accurate and detailed velocity/depth functions.

\section{ACKNOWLEDGMENTS}

We thank Warren Wood for his kind assistance in the use of his "P-Pick" normal moveout program. We acknowledge the input of Davis Falquist and Richard Carlson, and the assistance of the scientists and marine technicians of Leg 123, who helped acquire the data for this study.

\section{REFERENCES}

Buffler, R. T., 1990. Underway geophysics. In Gradstein, F. M., Ludden, J. N., et al., Proc. ODP, Init. Repts., 123: College Station, TX (Ocean Drilling Program), 13-25.

Carlson, R. L., Gangi, A. F., and Snow, K. R., 1986. Empirical reflection traveltime versus depth functions for the deep-sea sediment column. J. Geophys. Res., 91:8249-8266.

Diebold, J. B., and Stoffa, P. L., 1981. The traveltime equation, tau-p mapping, and inversion of common midpoint data. Geophysics, 46:238-254.

Dix, C. H., 1955. Seismic velocities from surface measurements. Geophysics, 20:68-86.

McMechan, G., and Ottolini, R., 1980. Direct observation of a p- $\tau$ curve in a slant stacked wavefield. SSA Bull., 44:1193-1207.

Phinney, R. A., Chowdhury, R. K., and Frazer, L. N., 1981. Transformation and analysis of record sections. J. Geophys. Res., 86:359-377.

Schultz, P. S., 1976. Velocity estimation by wave front synthesis [Ph.D. dissert.]. Stanford Univ., Stanford, CA.

1982. A method for direct estimation of interval velocities. Geophysics, 47:1657-1671. 
Schultz, P. S., and Claerbout, J. F., 1978. Velocity estimation and downward continuation by wavefront synthesis. Geophysics, 43:691-714.

Singh, S. C., West, G. F., and Chapman, C. H., 1989. On plane-wave decomposition: alias removal. Geophysics, 54:1339-1343.

Stoffa, P. L., Buhl, P., Diebold, J. B., and Wenzel, F., 1981. Direct mapping of seismic data to the domain of intercept time and ray parameter: a plane wave decomposition. Geophysics, 46:255-267.

Stoffa, P. L., Diebold, J. B., and Buhl, P., 1982. Velocity analysis for wide aperture seismic data. Geophys. Prospect., 30:25-57.
Taner, M. T., and Koehler, F., 1969. Velocity spectra-digital derivation and applications of velocity functions. Geophysics, 34:859-881.

Wood, W., 1989. Seisimic velocities of the Nankai Trough from ESP and Sonobuoy Data [M.S. thesis]. Univ. of Texas, Austin.

Date of initial receipt: 31 May 1990

Date of acceptance: 11 June 1991

Ms 123B-140

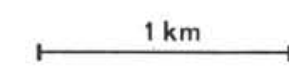

SE

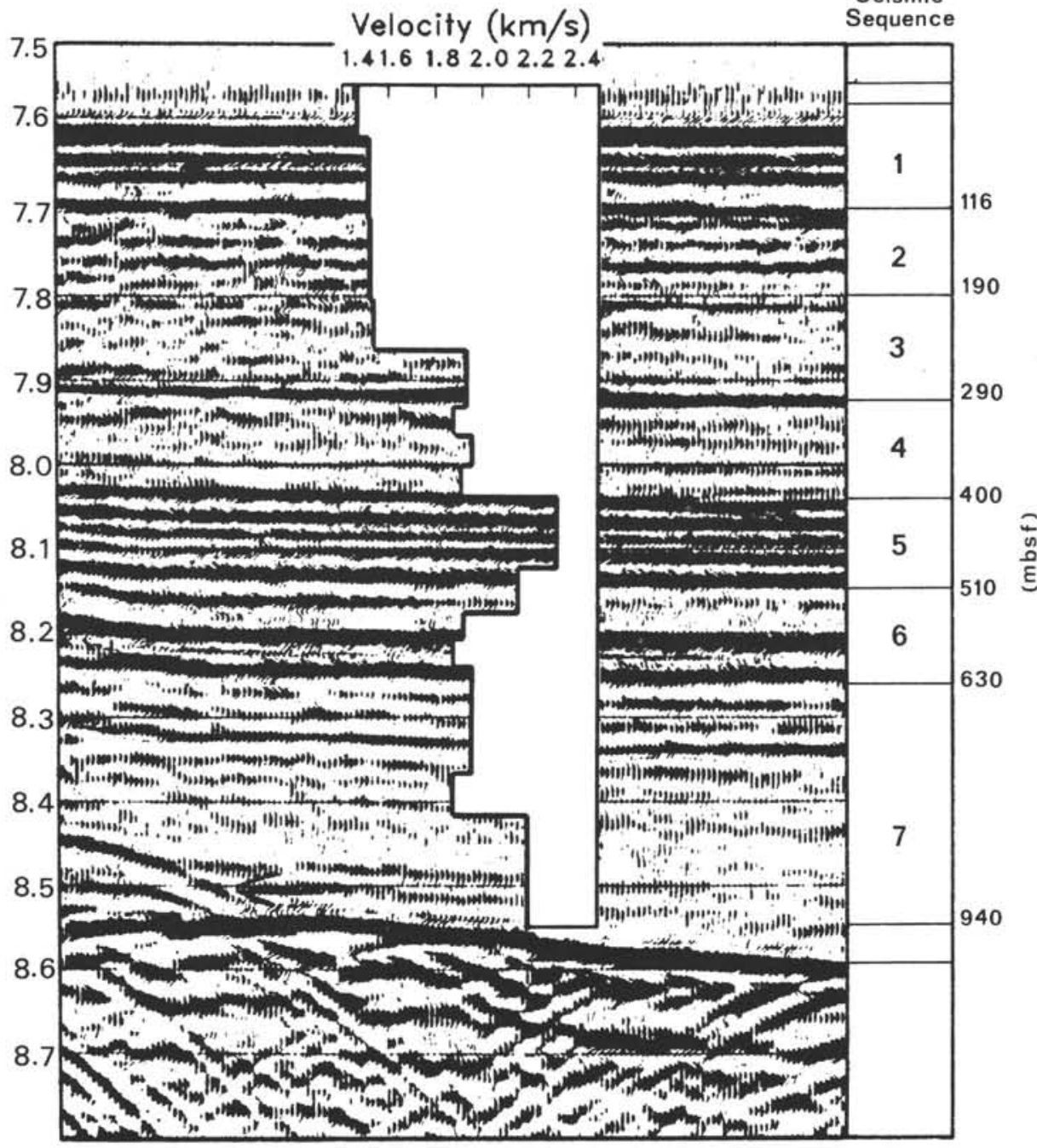

Site 765

$\downarrow$

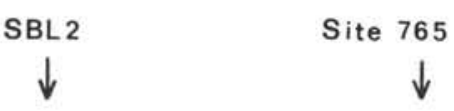

NW

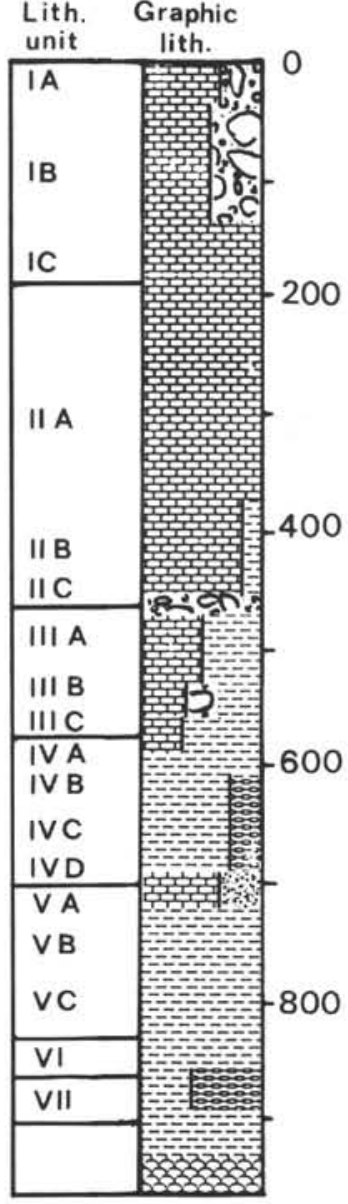

Figure 13. BMR Rig Seismic Line 56-23C with the sonobuoy velocity profile overlain. Depths to interpreted seismic sequences (Buffler, 1989 ) indicated at the right of the figure are based on the sonobuoy results. The graphic lithology column with major lithologic units is included at the right. 